\title{
Spatial variability in swelling of aggregated expansive clays
}

\author{
Faseel S. Khan ${ }^{1} \cdot$ Shahid Azam ${ }^{1}$
}

Received: 2 April 2016/Accepted: 23 May 2016/Published online: 14 June 2016

(C) Springer International Publishing Switzerland 2016

\begin{abstract}
Expansive clays exhibit swelling due to water intake along with spatial variations when the soils are initially aggregated. The resulting differential movements have severely affected civil infrastructure across the Canadian prairies. A large cell was designed, fabricated, calibrated and used to determine the spatial variability in swelling of expansive clays. Observations over a 2-year period indicated uneven vertical swelling and the presence of cracks in the center of the sample. The initial swelling (achieved within $24 \mathrm{~h}$ ) of about $8 \%$ gradually transitioned into primary swelling and registered a value of $109 \% \pm 8 \%$ after 2 years. The differential swelling was found to vary by $50 \%$ (from SP $=80 \%$ along the wall to $\mathrm{SP}=130 \%$ in the center) after 1 year and by $71 \%$ (from $\mathrm{SP}=96 \%$ along the wall to $\mathrm{SP}=167 \%$ in the center) after 2 years.
\end{abstract}

Keywords Expansive clays $\cdot$ Soil aggregates $\cdot$ Spatial variability $\cdot$ Large cell $\cdot$ Swelling potential

\section{Introduction}

Expansive clays exhibit large swelling movements associated with water imbibition. Such deformations are spatially variable due to an initially aggregated structure of the clays. Cracks reaching depths from 0.5 to $6.0 \mathrm{~m}$ below the ground surface are a permanent feature in most expansive deposits [8]. This is because cyclic wetting and drying

Shahid Azam

Shahid.Azam@URegina.CA

1 Environmental Systems Engineering, University of Regina, 3737 Wascana Parkway, Regina, SK S4S 0A2, Canada under ambient meteorological conditions result in alternate closing (lateral swelling movement due to preferential water ingress) and opening (lateral shrinkage due to weak bonding with the clay matrix) of the cracks [5]. Generally, vertical swelling depends on the distribution of cracks and is manifested in an uneven surface profile of the soil. Differential movements have damaged civil infrastructure in several urban centers (Edmonton, Regina and Winnipeg) and rural municipalities across the Canadian prairies. Typical examples include ruptured buried pipes, wavy road embankments, tilted utility poles, and fractured residential buildings. The associated maintenance cost for the region is not known but can be understood from the $\$ 2 \times 10^{6}$ per year for the repair of $850 \mathrm{~km}$ long water supply system in Regina alone.

The volume increase due to wetting is measured by determining the swelling potential (SP, volume change divided by initial volume) according to the ASTM standard test methods for one-dimensional swell or collapse of soils (D4546-14). This test is conducted using an oedometer ring with $60 \mathrm{~mm}$ diameter and $20 \mathrm{~mm}$ height under a nominal seating pressure. Although suitable for intact samples, the small dimensions of the conventional ring cannot capture spatial variations and the resulting uneven surface profile of an initially cracked soil. Moreover, confinement by the steel ring during this test restricts lateral volume changes, thereby resulting in a higher vertical SP. Data on SP of large samples are scarce, because such tests are usually costly, time consuming and difficult to set up. Abduljauwad and Al-Sulaimani [1] found comparable SP values for slab-on-grade using a laboratory test (steel tank of $500 \mathrm{~mm}$ sides) and a field test (steel plate of $760 \mathrm{~mm}$ sides). The use of a circular sample under no load for SP measurement of an initially cracked soil is not well documented in the literature. 
The main objective of this note was to understand the spatial variability in swelling of aggregated expansive clays. The schematics and calibration of a large cell (designed by Khan and Azam [6]) and the observations during testing are described. The vertical SP was measured at four locations along the circumference, whereas spatial variations in SP across the surface were measured after 1 and 2 years.

\section{Materials and methods}

The selected expansive clay belonged to an extensive deposit in Avonlea (latitude 50.0367 and longitude 105.0667), Saskatchewan, Canada. The geological setting and climatic conditions of the area were described earlier by Azam and Khan [3] and Imumorin and Azam [4], based on field investigations spanning over several years. In short, the surface layer (up to $300 \mathrm{~mm}$ ) of the 1-2 m thick deposit remains desiccated most of the year under the semiarid climate prevalent in the region. This layer is characterized by an aggregated morphology with individual clay clumps ranging from 50 to $100 \mathrm{~mm}$ in diameter.

The material was collected from the top surface using a shovel, put in plastic buckets and transported to the laboratory for testing. These large aggregates could not fit in the small dimensions of the conventional oedometer and, therefore, a large cell was needed. According to Khan and Azam [6], the material has a specific gravity of 2.85 with $72 \%$ of the particles smaller than $0.002 \mathrm{~mm}$. Furthermore, the high consistency limits (liquid limit $180 \%$ and plastic limit $60 \%$ ) and high natural water content (25\%) indicate not only the high water retention characteristics, but also the high swelling nature of the clay.

Figure 1 gives the schematic of the large cell $(600 \mathrm{~mm}$ diameter and $600 \mathrm{~mm}$ height). The cell was cut from a plexiglass tube $(6.5 \mathrm{~mm}$ thick) to observe the soil from the sides. The tube was fastened to a $12 \mathrm{~mm}$ thick base plate. A large diameter was selected to investigate spatial variations in swelling. Scales were attached at four locations (S1, S2, $\mathrm{S} 3$, and S4) to measure vertical SP along the sample circumference. The entire apparatus was routinely measured to identify possible bulging (due to lateral swelling) and shifting (due to vertical swelling) during testing and such movements were found to be non-existent. This was because of the weights that were added on top of the cell to counter the vertical shifting of the cell due to expected soil swelling.

Figure 2 gives the calibration of the large cell for circumferential and surface measurements. For side calibration (Fig. 2a), the cell was vertically aligned with the help of a bubble level: a water test was carried out to check for leaks. The water level in the cell was varied and measured at the (a)

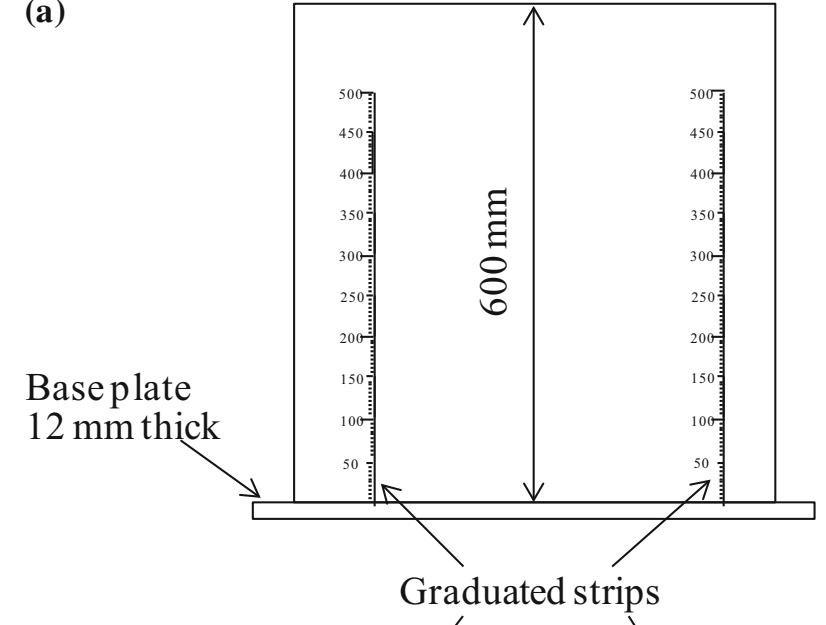

(b)

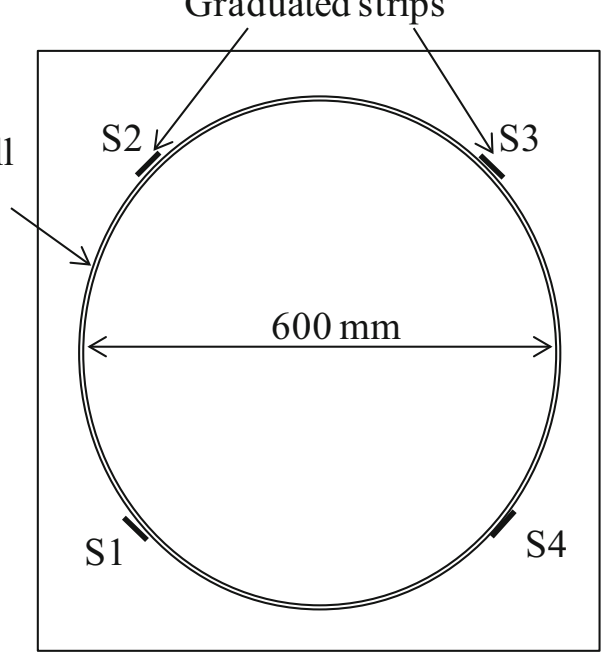

Fig. 1 Schematic of the large cell: a side elevation and $\mathbf{b}$ plan view

above-mentioned four locations to ensure that the cell dimensions remained constant with height. For surface calibration (Fig. 2b), a steel grid with hexagonal openings $(16 \mathrm{~mm} \times 13 \mathrm{~mm})$ was used: the rigidity of the grid precluded sagging. The center to center spacing of the openings was $32 \mathrm{~mm}$ in one direction and $26 \mathrm{~mm}$ in the other direction accounting to nearly 800 measuring points across the surface. A steel rod with a rubber stopper (to vertically align the rod) was carefully lowered to just touch the known water surface and the rod length from the mesh (corrected for mesh thickness) was converted to water height in the cell. The data from surface measurement were verified using those from the circumferential measurements.

The aggregated clay was gently pressed in the cell by lightly tamping with a rubber hammer to achieve a homogeneous sample pertaining to the field dry density of $1.1 \mathrm{~g} / \mathrm{cm}^{3}$ [3]. An initial sample height of $150 \mathrm{~mm}$ was used to ensure a height to diameter ratio of 0.25 according to the ASTM test procedure. A total of $73 \mathrm{~L}$ of distilled water (pertaining to the liquid limit of the soil) was swiftly added using $20 \mathrm{~L}$ water pails. A polythene 


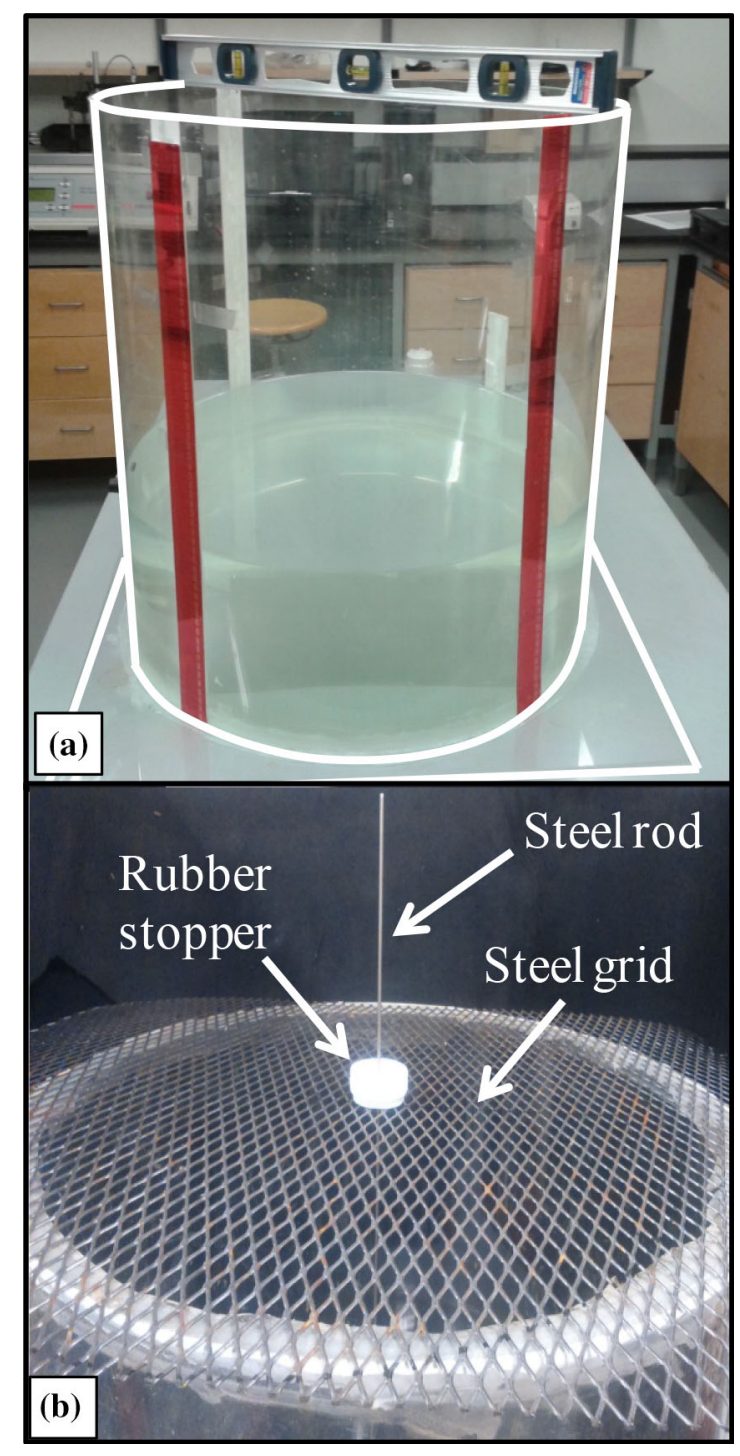

Fig. 2 Calibration of the large cell for: a side measurements and b surface measurements

sheet was used to cover the cell top for preventing evaporation loses. Lateral bulging was expected to be negligible due to rigidity of the plexglass cell $(6.5 \mathrm{~mm}$ thick) and also because swelling was not restricted in the vertical direction. The sample was observed and sample heights were noted from sides initially at short time intervals in the first day of measurements. The intervals were subsequently increased to daily measurements and weekly measurements. Likewise, the surface profile was measured after 1 and 2 years of inundation. This was achieved by the process described earlier for surface calibration with the following changes. The SP was calculated by dividing soil height by the initial height and cracks were mapped by carefully taking readings to avoid disturbance. The entire process of surface measurements was completed in $10 \mathrm{~h}$.

\section{Results and observations}

Figure 3 gives the side view of the cell at different time intervals. The sample showed uneven swelling after 1 year (Fig. 3a) that was further elaborated after 2 years (Fig. 3b). In an initially homogenous sample [6], the cracks are seen to be unevenly distributed: (1) negligible and tiny cracks in the upper layer due to sample saturation because water was added from the top; (2) numerous and large cracks in the middle layer due to ongoing swelling; and (3) fewer and smaller cracks in the bottom third due to marginal swelling caused by low sample hydration and overburden.

Figure 4 gives the top view of the cell at different time intervals. Cracks are seen mainly in the center due to differential swelling resulting from an absence of uniform seating load on the sample and wall friction along the circumference. This cracking pattern is different from the irregular polygonal shaped cracks normally observed during soil desiccation [9]. A visual comparison of the sample

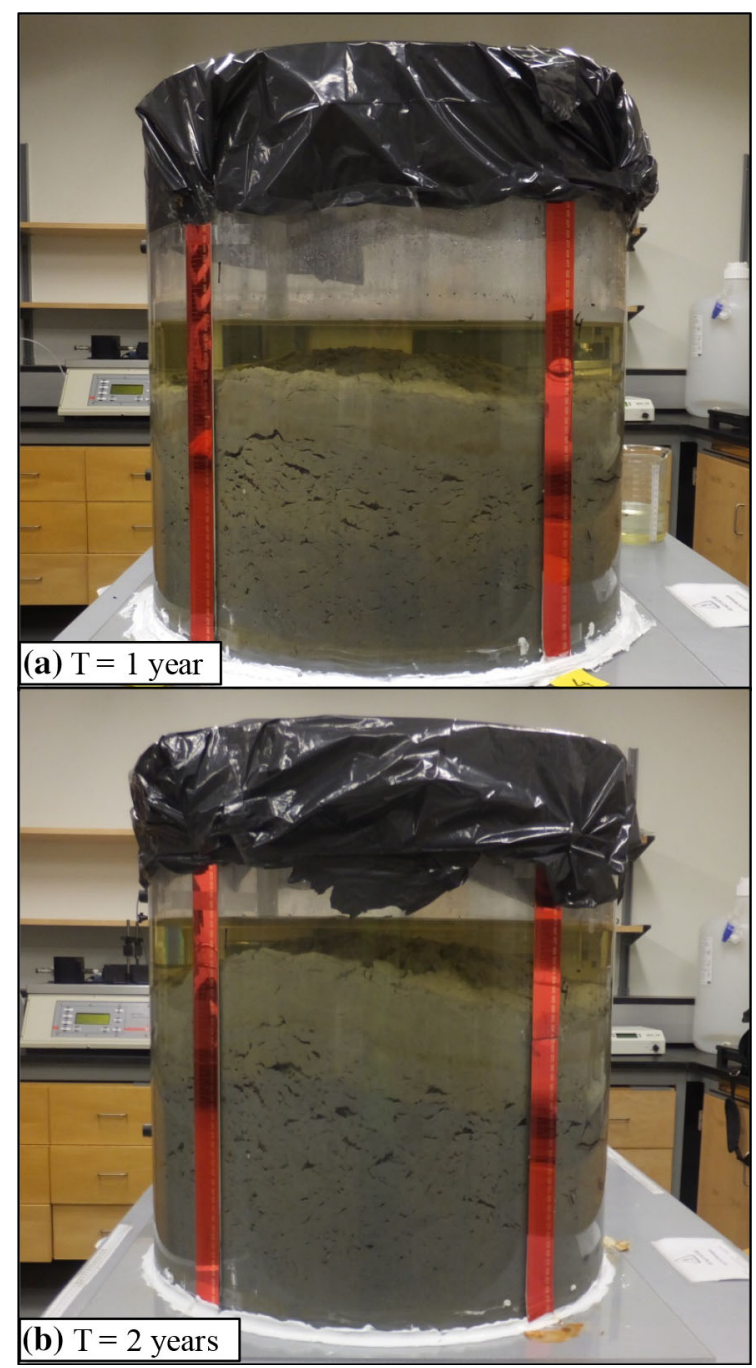

Fig. 3 Side view of the sample: $\mathbf{a}$ after 1 year and $\mathbf{b}$ after 2 years 


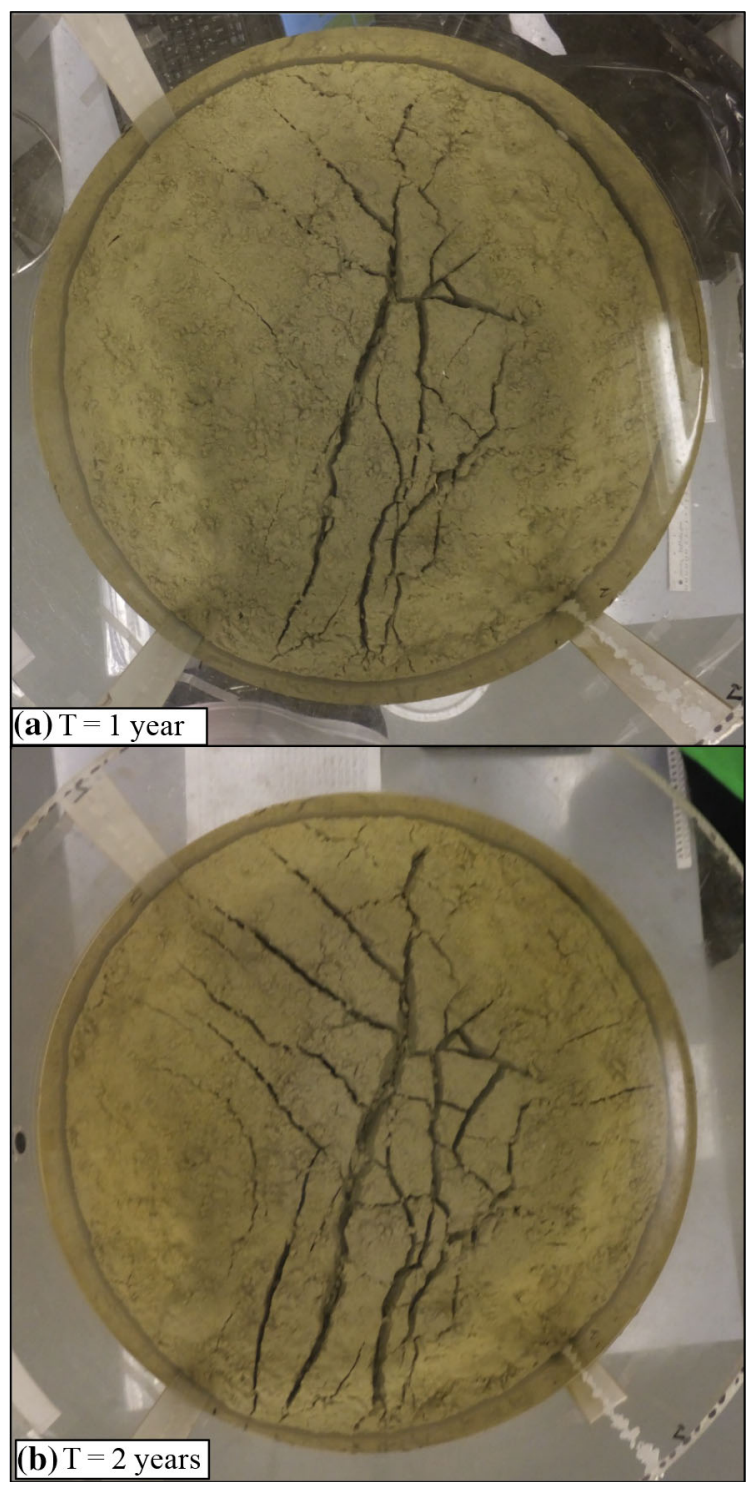

Fig. 4 Surface view of of the sample: $\mathbf{a}$ after 1 year and $\mathbf{b}$ after 2 years

after 1 year (Fig. 4a) with that after 2 years (Fig. 4b) indicates the crack size (width and depth) and branching increased over time. This was because of the increase in differential swelling as observed from the top.

Figure 5 shows the circumferential SP measurements at S1, S2, S3 and S4. A J-shaped curve was observed comprising two swelling regimes. The initial swelling (achieved within $24 \mathrm{~h}$ ) of $8 \pm 2 \%$ gradually transitioned into primary swelling and registered a value of $109 \pm 9 \%$ (or a maximum differential swelling of about $18 \%$ ) after 2 years. The initial swelling in the vertical direction was low because of lateral expansion of the soil aggregates in the cracks [2]. Once the cracks were closed, water slowly migrated inwards into the initially unsaturated aggregates and gradually hydrated these during primary swelling.

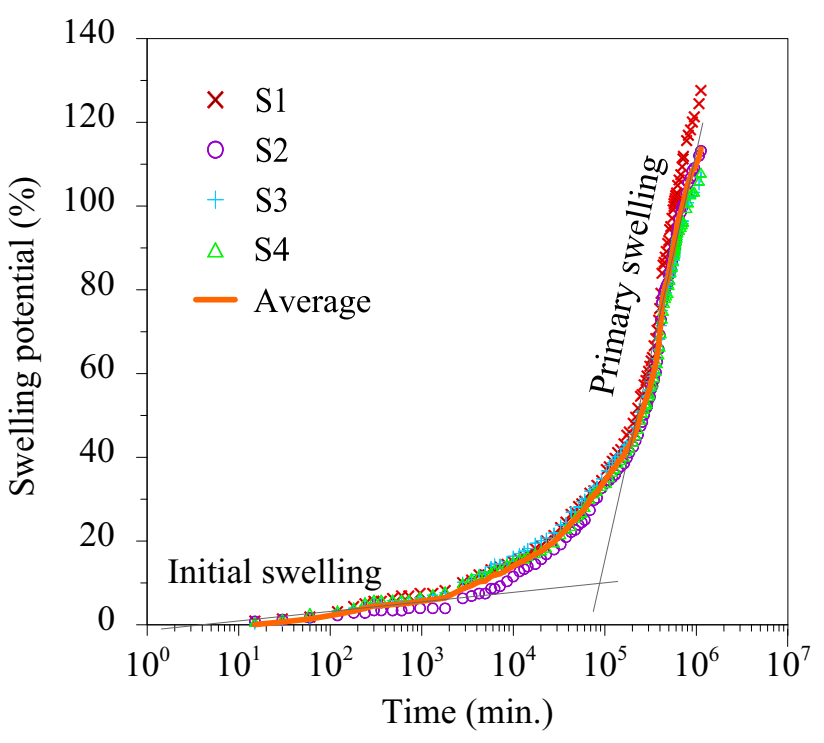

Fig. 5 Swelling potential versus time

According to Mitchell and Soga [7], hydration occurs due to adsorption of water molecules onto negatively charged clay particles, thereby pushing apart these platelets and causing an overall increase in soil volume. Furthermore, the gradual decrease in slope of the SP curves indicates that the sample is now entering the secondary swelling regime. This correlates with the presence of unhydrated clay particles primarily in the middle and bottom layers (Fig. 3) that are slowly being hydrated as the water traverses long paths in the large sample.

Figure 6 gives the surface measurements of SP in the form of 3D isometric views as well as contour maps. The differential swelling across the sample varied by $50 \%$ (ranging from $\mathrm{SP}=80 \%$ along the wall to $\mathrm{SP}=130 \%$ in the center) after 1 year (Fig. 6a) and by $71 \%$ (ranging from $\mathrm{SP}=96 \%$ along the wall to $\mathrm{SP}=167 \%$ in the center) after 2 years (Fig. 6b). The lower SP values along the wall are attributed to soil-wall friction and the presence of voids (Fig. 3) that are yet to be filled by swelling of the clay. These data corroborated well with the observed cracking pattern, that is, maximum cracking in the center and minimum along the circumference of the sample.

\section{Summary and conclusions}

Knowledge of volume changes is pivotal for developing sustainable management protocols for civil infrastructure constructed in and on expansive clays. This is particularly true for lightly loaded structures that experience distress and damage due to differential movements of the supporting soils. A large cell was designed, fabricated, calibrated and used to determine the spatial variability in 


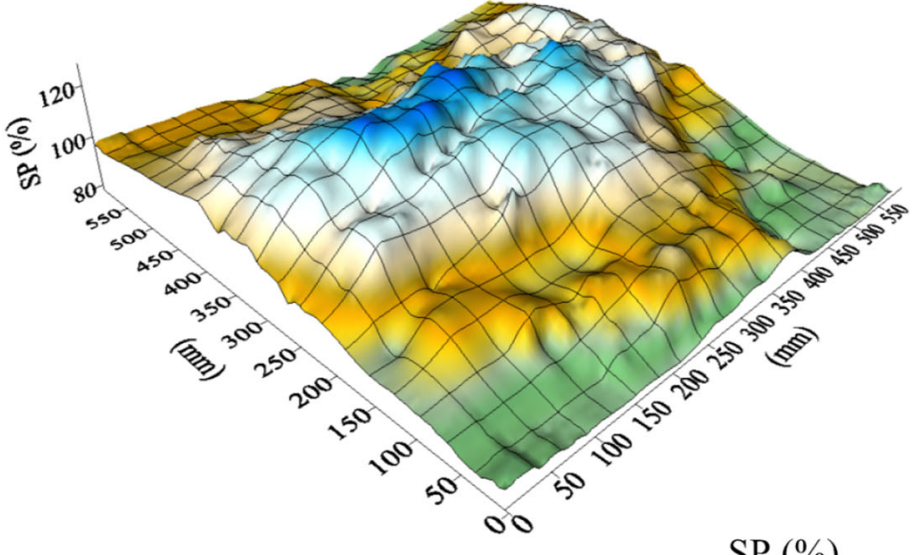

(a) $\mathrm{T}=1$ year

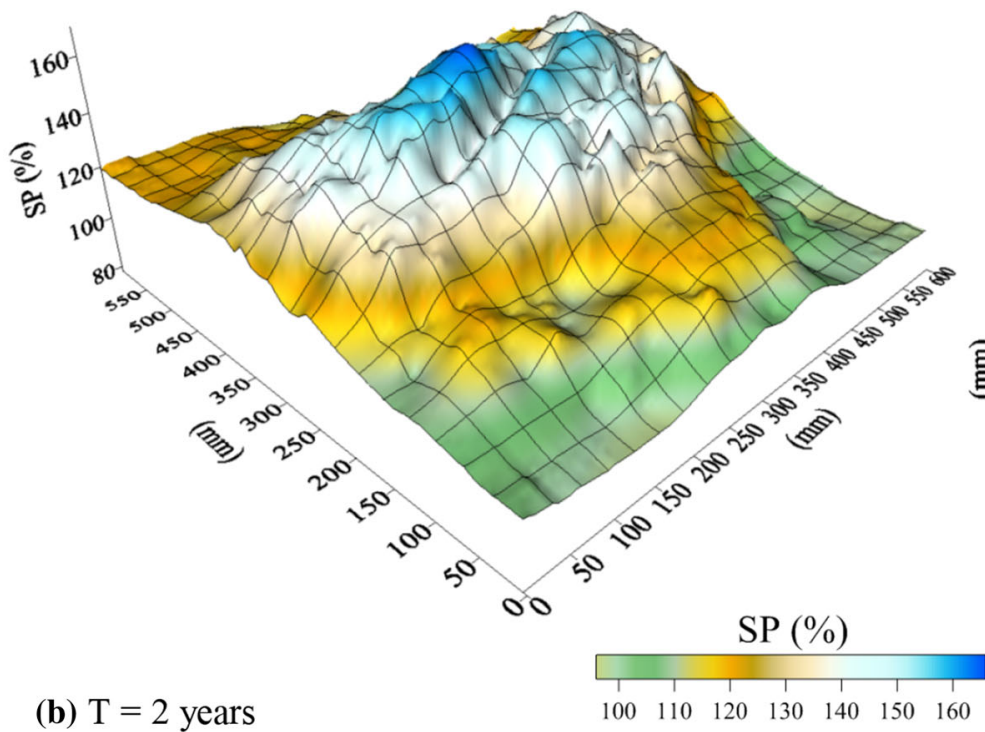

(mm)

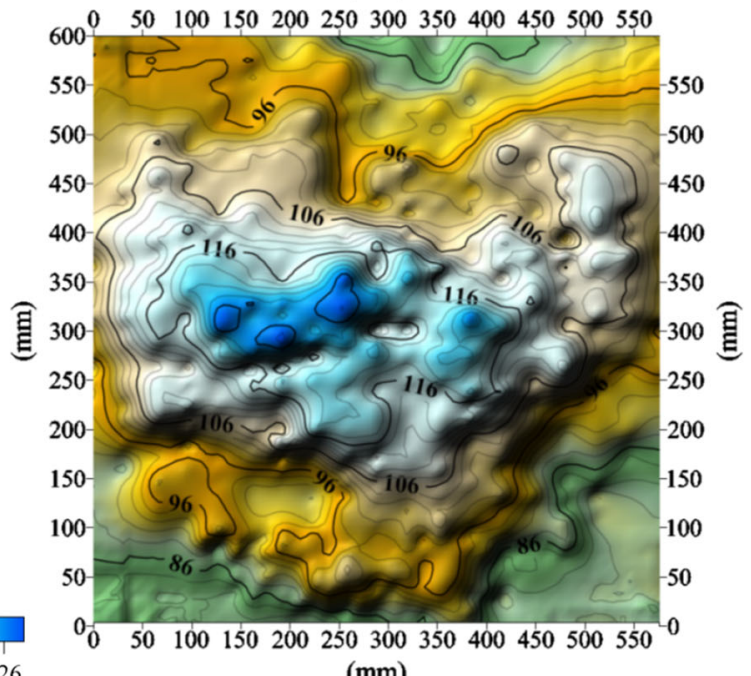

(mm)

(mm)

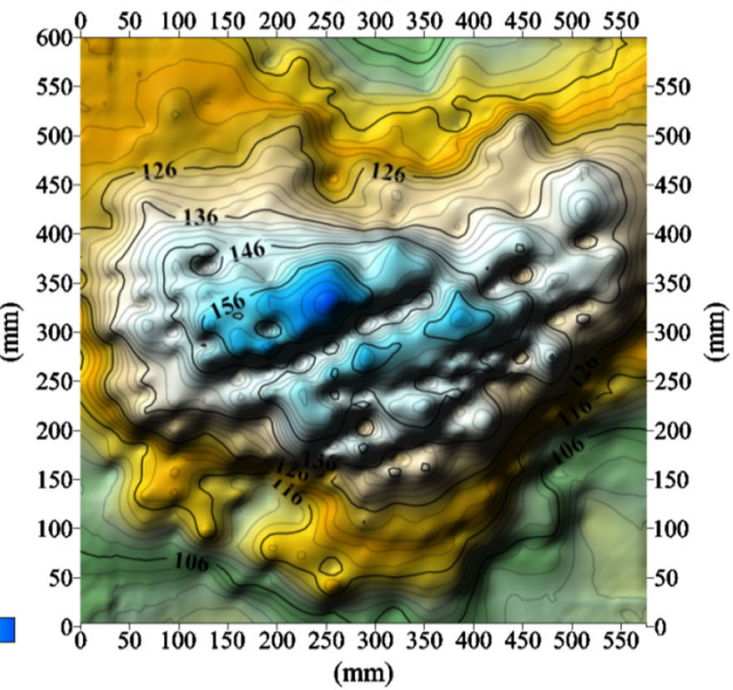

Fig. 6 Spatial variation of swelling potential: a after 1 year and $\mathbf{b}$ after 2 years

swelling of aggregated expansive clays. Observations over a 2-year period indicated uneven vertical swelling and the presence of cracks in the center of the sample. The initial swelling (achieved within $24 \mathrm{~h}$ ) of about $8 \%$ gradually transitioned into primary swelling and registered a value of $109 \pm 8 \%$ after 2 years. The differential swelling was found to vary by $50 \%$ (from SP $=80 \%$ along the wall to $\mathrm{SP}=130 \%$ in the center) after 1 year and by $71 \%$ (from $\mathrm{SP}=96 \%$ along the wall to $\mathrm{SP}=167 \%$ in the center) after 2 years. These data are useful for the design and construction of new facilities and for ensuring an uninterrupted use of existing infrastructure.

Acknowledgments The authors would like to thank the University of Regina for providing laboratory space and Mr. Peter Gutiw for helping during the various test stages. Thanks to Canada Foundation for Innovation for providing funding support to develop the equipment.

\section{References}

1. Abduljauwad SN, Al-Sulaimani GJ (1993) Determination of swell potential of Al-Qatif clay. Geotech Test J 16(4):469-484

2. Azam S, Abduljauwad SN, Al-Shayea NA, Al-Amoudi OSB (2000) Effects of calcium sulfate on swelling potential of an expansive clay. Geotech Test J 23(4):389-403

3. Azam S, Khan F (2014) Geohydrological properties of selected badland sediments in Saskatchewan, Canada. Bull Eng Geol Environ 73(2):389-399

4. Imumorin P, Azam S (2011) Effect of precipitation on geologic development of badlands in arid regions. Bull Eng Geol Environ 70(2):223-229

5. Ito M, Azam S (2013) Engineering properties of a vertisolic expansive soil deposit. Eng Geol 152(1):10-16 
6. Khan FS, Azam S (2014) Determination of swelling potential of a fissured expansive clay in a large cell. In: 67th Canadian geotechnical conference, Regina

7. Mitchell JK, Soga K (2005) Fundamentals of soil behaviour. Wiley, New York
8. Morris PH, Graham J, Williams DJ (1992) Cracking of drying soils. Can Geotech J 29:263-277

9. Tang C-S, Cui Y-J, Shi B, Tang A-M, Liu C (2011) Desiccation and cracking behaviour of clay layer from slurry state under wetting-drying cycles. Geoderma 166(1):111-118 